\title{
The Relationship of Gin Date to Aflatoxin Contamination of Cottonseed in Arizona
}

\author{
C. H. Bock and P. J. Cotty, USDA-ARS-SRRC, 1100 Robert E. Lee Boulevard, New Orleans, LA 70124
}

\begin{abstract}
Bock, C. H., and Cotty, P. J. 1999. The relationship of gin date to aflatoxin contamination of cottonseed in Arizona. Plant Dis. 83:279-285.

During 1995 and 1996, a commercial gin in western Arizona ginned seed cotton on a field-byfield basis. Seed from each field was kept separate until sampled and analyzed for aflatoxin content according to Arizona Commercial Feed Law. This gave a comprehensive view of fieldto-field variability in aflatoxin content as the season progressed. Regression analysis indicated significant relationships between gin date and aflatoxin content in both years: aflatoxin increased with later ginnning. Overall, 89 and 79\% of seed lots exceeded $20 \mathrm{ppb}$ in 1995 and 1996, respectively. No field ginned after Julian Day (JD) 273 in 1995 or after JD 267 in 1996 had an aflatoxin content $<20 \mathrm{ppb}$. Means separation confirmed later ginned crops had significantly greater aflatoxin content $(P=0.05)$. In 1996 , transgenic $B t$ and non- $B t$ cottonseed were similarly contaminated. Mean aflatoxin content of $B t$ cottonseed in 1996 was 413 ppb and that of non- $B t$ cottonseed was $598 \mathrm{ppb}$. These observations suggest that, in Arizona, losses from aflatoxin contamination of cottonseed can be reduced by early harvest.
\end{abstract}

Aflatoxins are potent mycotoxins produced by fungi in Aspergillus section flavi. The toxic effect of aflatoxins on humans and other animals is well known (7); thus, many countries regulate the quantity of aflatoxins allowed in foods and feeds (17). Aspergillus flavus Link:Fr. infects many oilseed crops and is frequently, as with cottonseed, the primary cause of aflatoxin contamination (13).

When cottonseed is crushed for oil, the remaining meal then competes with other vegetable meals in the livestock feed market. During crushing, toxin is concentrated about twofold in the meal. In the U.S., both cottonseed and cottonseed meal may be sold at a premium for dairy feed only if the aflatoxin content does not exceed $20 \mathrm{ppb}$ (17). Seed and meal exceeding $300 \mathrm{ppb}$ aflatoxin may not be used for beef cattle feed.

In the southwestern U.S., aflatoxin contamination of cottonseed frequently occurs in furrow-irrigated cotton. Irrigation can influence aflatoxin contamination, particularly if continued into the harvest season (19). Indeed, field plot and laboratory observations suggest crops harvested later tend to have greater contamination (8). Cotton is indeterminate; the first bolls to mature and open are exposed to the envi-

Corresponding author: Peter J. Cotty; E-mail: pjcotty@nola.srrc.usda.gov

Accepted for publication 1 December 1998.

Publication no. D-1999-0115-01R

This article is in the public domain and not copyrightable. It may be freely reprinted with customary crediting of the source. The American Phytopathological Society, 1999. ronment while later bolls are developing. Bolls produced closer to the ground frequently contain the greatest aflatoxin contamination (3). These bolls are both the first to open and the closest to irrigation water (19).

Contamination is thought to occur in two phases $(4,8)$ : the first occurs prior to seed maturity; the second after maturity. Insect damage, particularly pink boll worm damage (Pectinophora gossypiella Lepidoptera: Gelechiidae) is associated with the first phase. Bolls infected during this phase frequently produce seed that exhibit bluegreen-yellow-fluorescence (BGYF) of the lint $(3,12)$. The second phase occurs after seed maturity, and involves direct infection of the seed by A. flavus. This process is favored by warm, moist conditions $(4,16)$. Contamination of some bollworm-resistant Bt cottonseed lots in 1995 was attributed to the second phase of contamination (11). During the second phase, the aflatoxin content of seed initially infected during the first phase may also increase. Thus, harvest date may be an important factor influencing final aflatoxin content.

The harvest season in Arizona typically extends over several months. Increased costs of late irrigation and pest control and losses associated with crop weathering may offset benefits of increased yield accrued from continued crop development. It is not clear how harvest date impacts aflatoxin contamination in the commercial setting. During 1995 and 1996, collaboration with a commercial gin afforded the analysis of the impact of gin date on aflatoxin content. The result is a clear association between harvest date and seed aflatoxin content that should be considered when developing integrated management systems for the control of aflatoxin contamination of cottonseed.

\section{MATERIALS AND METHODS}

Data collection and sample analysis. Cottonseed from a gin cooperative in the Mohawk Valley in western Arizona was assayed for aflatoxin on a field-by-field basis. Thirty-eight and 101 fields were assayed in 1995 and 1996, respectively. Aflatoxin values reported here are the values used in commerce and were determined as mandated by the Arizona Commercial Feed Law (2). Cottonseed lots not sent to an oil mill were sampled at the gin for subsequent aflatoxin analysis at a commercial laboratory. Samples were taken from the processing line immediately after ginning, with a robotic in-line sampler. For each field, small samples (75 to $125 \mathrm{~g}$ ) were taken at regular intervals and combined to make a composite sample (12 to $18 \mathrm{~kg}$ per field). Law mandates that no more than 100 tons of cottonseed may be sampled per analysis; therefore, maximum field size was less than 100 acres. Seed sent to oil mills typically is not analyzed by the gin. Aflatoxin contents of seed lots sent to oil mills were determined by the mill, using official methods (1). The aflatoxin values were averaged where multiple truckloads of seed were harvested from a single field. In 1995, growers were asked to mark modules and indicate field of origin. In 1996, growers were also asked to supply

Table 1. The number of cottonseed lots sampled, ginning periods, and range of aflatoxin contamination in the Mohawk Valley, Arizona, in 1995 and 1996

\begin{tabular}{lcc}
\hline & \multicolumn{2}{c}{ Year } \\
\cline { 2 - 3 } Sample information & $\mathbf{1 9 9 5}$ & $\mathbf{1 9 9 6}$ \\
\hline Number of cottonseed lots & 35 & 101 \\
Ginning periods & 1 September to 4 December & 9 August to 4 December \\
Total days & 94 & 117 \\
Aflatoxin contamination $(\mathrm{ppb})$ & 2 to 2,375 & 0 to 2,200 \\
\hline
\end{tabular}

z Julian Day for $1995=244-338$, for $1996=221-338$. 
harvest date and cultivar. In both years, all seed lots ginned were included except those intended for use as planting seed, for which aflatoxin content is not analyzed.

Weather data. Daily weather data for 1995 and 1996 were obtained from the Welton-Mohawk Irrigation Development District (WMIDD). Weather variables provided included maximum and minimum temperatures, rainfall, and daily dew point temperature. Dew was assumed to have formed when the temperature fell below the dew point temperature. Mean weather data were obtained from the daily weather data for each week to provide weekly averages from 13 stations dispersed throughout the production area. Evaporation data were obtained from a single central location.

Data analysis. Data were analyzed with Statistica (StatSoft Program, Tulsa, Oklahoma, 1994) and Microsoft Excel (version 5.0). Aflatoxin data were regressed against
Table 2. The number and proportion of cottonseed lots with various aflatoxin contents produced in the Mohawk Valley, Arizona

\begin{tabular}{lccc}
\hline \multirow{2}{*}{$\begin{array}{l}\text { Aflatoxin } \\
\text { content (ppb) }\end{array}$} & \multicolumn{3}{c}{ Year } \\
\cline { 2 - 4 } & $\mathbf{1 9 9 5}$ & $\mathbf{1 9 9 6}$ & $\mathbf{1 9 9 5 + \mathbf { 1 9 9 6 }}$ \\
\hline $0-19.9$ & $4(11)^{\mathrm{z}}$ & $21(21)$ & $25(18)$ \\
$20-300$ & $15(43)$ & $50(49)$ & $65(48)$ \\
$>300$ & $16(46)$ & $30(30)$ & $46(34)$ \\
Total & 35 & 101 & 136 \\
\hline
\end{tabular}

${ }^{\mathrm{z}}$ Numbers in parentheses are the percent seed lots in each category.

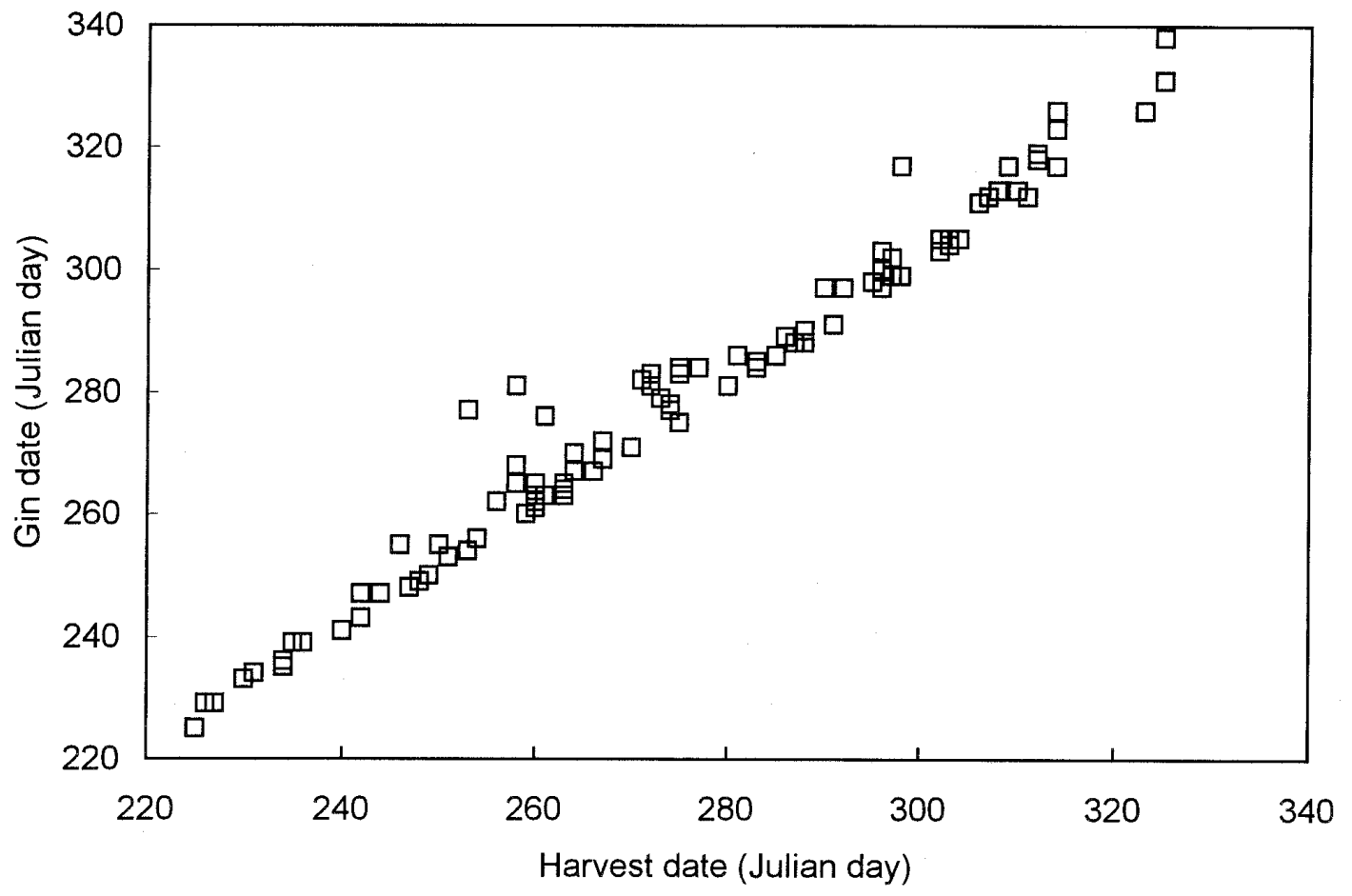

Fig. 1. Relationship between harvest date and gin date of cottonseed lots produced in the Mohawk Valley, Arizona, in 1996.

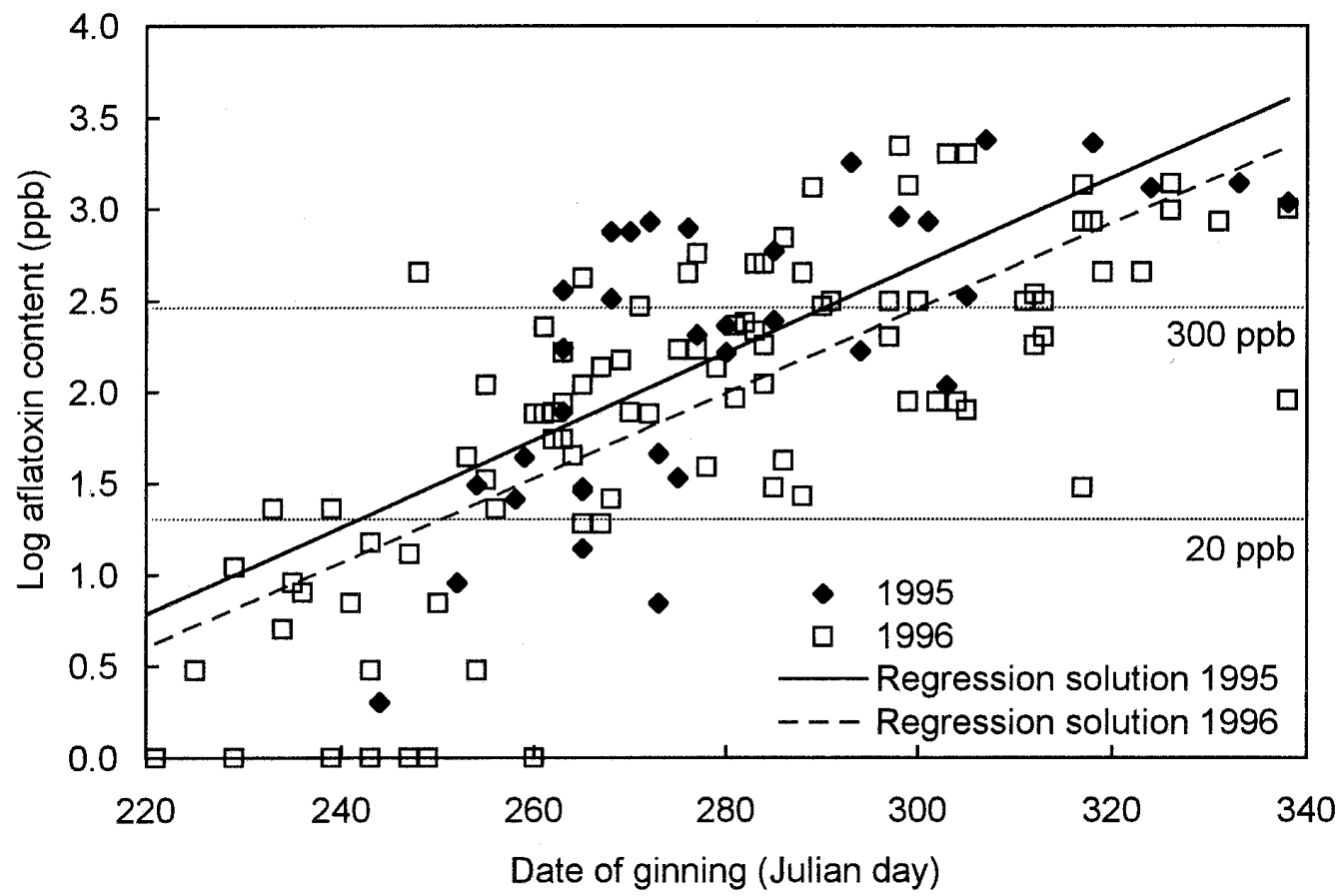

Fig. 2. Relationship between gin date and aflatoxin content of cottonseed harvested in the Mohawk Valley, Arizona, in 1995 and 1996. Regression solutions shown are those described for log transformed aflatoxin contents for individual seed lots (see Table 3). 
gin date, rather than harvest date, because in 1995 harvest dates were not provided. Aflatoxin values were $\log$ transformed prior to regression analysis and a test of parallelism was used to assess differences between the regression solutions from 1995 and 1996. In 1995, ginning of transgenic $B t$ cottonseed lots was delayed due to gin clean-out requirements. Therefore, these fields were excluded from the regression analysis. In 1996, management of $B t$ cultivars at the gin was the same as for other cultivars; thus, seed lots of NuCOTN $33^{\mathrm{B}}$ were included in the regression analysis. In order to compare aflatoxin contents of seed from different ginning periods, we averaged a minimum of five consecutive aflatoxin content values and generated a table of means versus ginning period. Samples ginned on the same date were not split between means, and thus the mean values were representative of five to nine values. Means separation was performed after the data were $\log$ transformed with the Spjotvall and Stoline test (20; $P=0.05)$. Regression analysis was also performed on the mean data. In 1996 (the only year for which cultivar data were available) the observed and predicted aflatoxin contents (based on the regression solution for individual cottonseed lots in 1996) for each cultivar were compared with a $t$ test $(P=0.05)$. Comparisons were made only if there were more than four seed lots for that cultivar.

\section{RESULTS}

The total number of harvested fields examined, the ginning periods, and the range of aflatoxin contamination in 1995 and 1996 are shown in Table 1. Gin date closely followed harvest date for all fields in 1996 (Fig. 1). In both years, aflatoxin content ranged from $<20$ to $>2,000 \mathrm{ppb}$. The percentage of seed lots with aflatoxin contamination below the maximum level allowed for dairy use (20 ppb) was $11 \%$ in 1995 and 21\% in 1996 (Table 2). Contamination exceeded $300 \mathrm{ppb}$ in 46 and $30 \%$ of cottonseed lots ginned in 1995 and 1996, respectively.

Aflatoxin contents of cottonseed lots were significantly correlated with gin date in both 1995 and 1996, with aflatoxin increasing with later ginning (Fig. 2 and Table 3). The relationship with the log transformed data for individual cottonseed lots was linear in both $1995\left(R^{2}=0.49\right)$ and $1996\left(R^{2}=0.55\right)$ and highly consistent between years (test of parallelism indicated no significant difference, $P=0.05$ ). The relationship between aflatoxin means (5 to 9 lots per mean) and gin date was best described by a linear model for $1995\left(R^{2}=\right.$ 0.95), and an exponential model for 1996 $\left(R^{2}=0.81\right)$. Separation of means confirmed crops harvested later had significantly greater aflatoxin than those harvested early (Table 4).

Based on the logarithmic regression of individual cottonseed lots, the predicted daily increase in 1995 was only $1.82 \mathrm{ppb}$ on Julian Day (JD) 250, but by JD 291 it was $17.56 \mathrm{ppb}$. In 1996, the predicted daily increases were 0.88 and $7.68 \mathrm{ppb}$ per day on JD 250 and 291, respectively. No cottonseed ginned after JD 273 in 1995 or after JD 267 in 1996 had an aflatoxin content $<20 \mathrm{ppb}$, and no cottonseed ginned after JD 303 in 1995 had $<300 \mathrm{ppb}$ (Fig. 3A and B, respectively). In 1996, a single cottonseed lot was ginned on JD 338 with 90 ppb aflatoxin, but $89 \%$ of the fields with $<300$ ppb had been ginned by JD 303 .

Mean weekly weather data and mean weekly aflatoxin data for weeks ending JD 224 to 343 for 1995 and 1996 are shown in Figures 4 and 5, respectively. Weather station mean weekly maximum temperatures were consistently above $25^{\circ} \mathrm{C}$ and the number of nights in which temperature dropped below the dew point ranged from 0 to 7 . Mean weekly aflatoxin increased until the week ending JD 308 in 1995 and 1996. After this date, mean weekly aflatoxin levels were based on fewer than three values and the trend was less clear. Evaporation steadily decreased as the season progressed.

Both transgenic $B t$ and non- $B t$ cottons were grown in 1996 (Table 5). No cultivar information was available in 1995. SureGrow 125 was the most commonly grown cultivar, constituting $32 \%$ of the seed lots analyzed. Cultivars Deltapine 5415 and Sure-Grow 501 were also widely grown. No cultivar was free from aflatoxin. Mean aflatoxin content for all varieties exceeded $20 \mathrm{ppb}$. For no cultivar at any time was the actual aflatoxin significantly different from the predicted aflatoxin content. In 1995, only three $B t$ cottonseed lots were available for analysis (Table 6). Aflatoxin ranged from 600 to $7,000 \mathrm{ppb}$, and among the non- $B t$ lots from 2 to 2,375 ppb (37 lots). However, in 1996, when eight trans-

Table 3. The relationship between aflatoxin content of ginned cottonseed and gin date in Arizona in 1995 and 1996

\begin{tabular}{|c|c|c|c|c|c|}
\hline Year & Data type & Transformation & Regression model & Regression solution & $R^{2}$ \\
\hline \multirow[t]{4}{*}{1995} & Individual seed lots & Untransformed & Linear & $y=18.99 x-4818.6$ & 0.47 \\
\hline & & $\log$ & Linear & $\log y=0.024 x-4.47$ & 0.49 \\
\hline & Sample means ${ }^{\mathrm{z}}$ & Untransformed & Linear & $y=17.68 x-4485.9$ & 0.95 \\
\hline & & Untransformed & Exponential & $y=0.00008 \mathrm{e}^{0.0538 \mathrm{x}}$ & 0.76 \\
\hline \multirow[t]{4}{*}{1996} & Individual seed lots & Untransformed & Linear & $y=8.89 x-2151.5$ & 0.27 \\
\hline & & $\log$ & Linear & $\log y=0.023 x-4.52$ & 0.55 \\
\hline & Sample means & Untransformed & Linear & $y=8.89 x-2154.5$ & 0.68 \\
\hline & & Untransformed & Exponential & $\mathrm{y}=0.00007 \mathrm{e}^{0.0522 \mathrm{x}}$ & 0.81 \\
\hline
\end{tabular}

${ }^{\mathrm{z}}$ For both years means were of a minimum of five consecutive values. Values of cottonseed lots ginned on a single date were not split between means.

Table 4. Mean aflatoxin content of cottonseed ginned over consecutive periods ${ }^{\mathrm{x}}$ in the Mohawk Valley, Arizona, in 1995 and 1996

\begin{tabular}{cccccc}
\hline Year & $\begin{array}{c}\text { Harvest period } \\
\text { (Julian Day) }\end{array}$ & $\begin{array}{c}\text { Mean aflatoxin } \\
\text { content (ppb) }\end{array}$ & $\begin{array}{c}\text { Samples } \\
\text { (no.) }\end{array}$ & $\begin{array}{c}\text { Percent seed lots } \\
\text { below 20 ppb }\end{array}$ & $\begin{array}{c}\text { Range of aflatoxin } \\
\text { content (ppb) }\end{array}$ \\
\hline 1995 & $244-259$ & $22 \mathrm{~b}^{\mathrm{z}}$ & 5 & 40 & $2-44$ \\
& $263-265$ & $114 \mathrm{ab}$ & 6 & 17 & $14-380$ \\
$268-273$ & $396 \mathrm{ab}$ & 7 & 14 & $7-850$ \\
$275-280$ & $284 \mathrm{ab}$ & 5 & 0 & $34-785$ \\
$285-298$ & $741 \mathrm{ab}$ & 5 & 0 & $168-1,800$ \\
& $1,148 \mathrm{a}$ & 9 & 0 & $108-2,375$ \\
& $301-338$ & $3 \mathrm{~g}$ & 5 & 100 & $0-11$ \\
$221-229$ & $11 \mathrm{~g}$ & 6 & 67 & $0-23$ \\
$233-239$ & $6 \mathrm{fg}$ & 6 & 100 & $0-15$ \\
$241-247$ & $101 \mathrm{efg}$ & 5 & 60 & $0-450$ \\
$248-254$ & $48 \mathrm{cdefg}$ & 5 & 20 & $0-109$ \\
$255-260$ & $110 \mathrm{cdef}$ & 9 & 0 & $76-227$ \\
$261-263$ & $125 \mathrm{cdef}$ & 6 & 33 & $79-421$ \\
$264-267$ & $125 \mathrm{cdef}$ & 5 & 0 & $39-570$ \\
$268-272$ & $279 \mathrm{cde}$ & 5 & 0 & $92-240$ \\
$275-278$ & $185 \mathrm{cde}$ & 5 & 0 & $110-500$ \\
$279-282$ & $301 \mathrm{cde}$ & 5 & 0 & $27-690$ \\
$283-284$ & $320 \mathrm{~cd}$ & 6 & 0 & $200-1,296$ \\
$285-288$ & $436 \mathrm{~cd}$ & 6 & 0 & $79-2,200$ \\
$289-297$ & $804 \mathrm{~cd}$ & 5 & 0 & $180-341$ \\
$298-302$ & $1041 \mathrm{~cd}$ & 6 & 0 & $30-1,352$ \\
$303-305$ & $269 \mathrm{c}$ & 5 & 0 & $90-1,366$ \\
\hline $311-313$ & $706 \mathrm{c}$ & 5 & 0 &
\end{tabular}

${ }^{\mathrm{x}}$ For both years averages were of a minimum of five consecutive values.

${ }^{y}$ Means for each year with a common letter were not significantly different $(P=0.05)$, using the Spjotvall and Stoline test (20).

${ }^{\mathrm{z}}$ The separation of means was performed with $\log$ transformed data. 
genic $B t$ cotton crops were analyzed during the period JD 280 to 337 the mean aflatoxin content was $413 \mathrm{ppb}$ (range 92 to $1,000 \mathrm{ppb}$ ), while that of the 34 non- $B t$ cottonseed lots ginned during the same period was $598 \mathrm{ppb}$ (range 27 to 2,200). Correlation analysis between gin date and aflatoxin content of $B t$ cotton showed a positive relationship $(r=0.88, P=0.05)$ similar to that seen with non- $B t$ cottons.

\section{DISCUSSION}

The present study is the first documentation of the severe impact harvest date has on aflatoxin contamination of commercial cottonseed. Cottonseed harvested later in the season has a greater risk of unacceptable aflatoxin contamination. This confirms field plot observations on cotton (8) and corn (15). However, the effect of harvest date in the present study exceeds what might be anticipated from the field plot studies. In both 1995 and 1996, most cottonseed lots exceeded the maximum aflatoxin content $(20 \mathrm{ppb})$ permissible for dairy feed and a large proportion exceeded that allowed for beef cattle feed (300 ppb).

Programs directed at limiting aflatoxin contamination of cottonseed need to consider potential harvest date influences. In the Mo- hawk Valley in 1995 and 1996, cottonseed harvested and ginned later than JD 273 had a greater than $50 \%$ chance of exceeding $20 \mathrm{ppb}$ (Fig. 3A and B). In addition to minimizing the risk of aflatoxin contamination, early harvest reduces overwintering insect pests (14) and lint weathering (thus improving lint grade), and increases value (21). Previous observations suggested that, once harvested, cotton should be ginned in a timely manner (5, 18). In the present study, ginning closely followed harvest date. Late season irrigation can provide adequate moisture for fungal activity and increased aflatoxin production (19). However, weather observa-
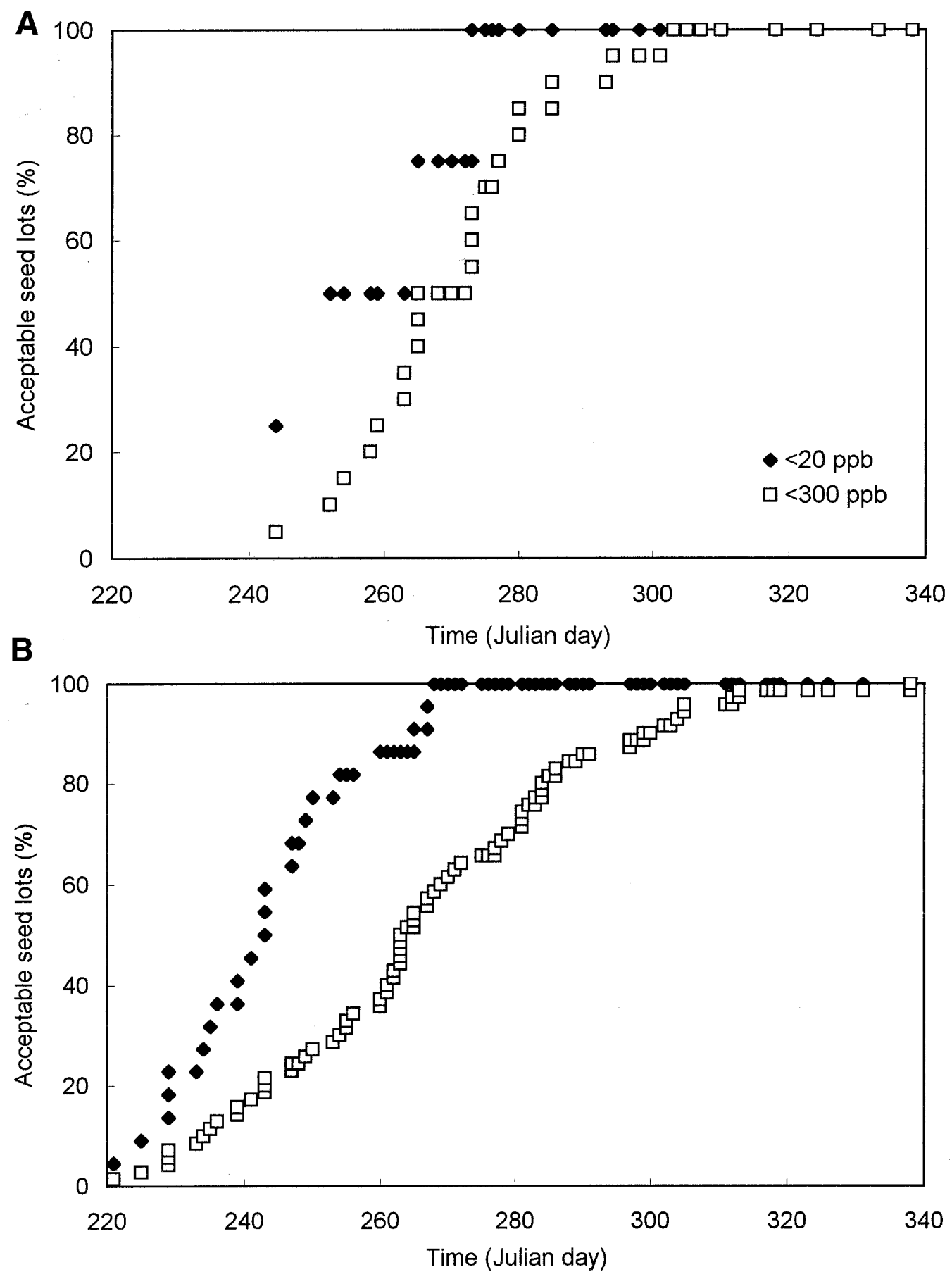

Fig. 3. The cumulative percentage of crops ginned with aflatoxin content <20 ppb and <300 ppb in (A) 1995 and (B) 1996 in the Mohawk Valley, Arizona. 
tions made during the present study suggest that even in the absence of irrigation, sufficient moisture (in the form of dew or high relative humidity) is available to drive aflatoxin increases.

In the present study, a commercial gin segregated cottonseed lots on a field-byfield basis. At most gins, seed from different fields are co-mingled. Segregation can result in increased numbers of seed lots with acceptable aflatoxin content, and may be an additional, cost-effective, aflatoxin management tool. In this study, segregation resulted in acceptable seed lots when mean toxin contents exceeded $20 \mathrm{ppb}$ between JD 244 and 273 in 1995, and JD 221 and 267 in 1996 (Fig. 2 and Table 4).

The relationship between harvest date and the log transformed data for individual cottonseed lots was linear. Thus, the rate of contamination actually increases as the season progresses, and delayed harvest not only risks increased aflatoxin, but the quantity of contamination forming during a defined period will be greater later in the season. The regression solutions for the mean aflatoxin data (Table 3) in 1995 (linear) and in 1996 (exponential) differed. Such differences may be attributable to both environmental and management

\section{- Maximum temperature - Mean temperature $\cdots$-...-Minimum temperature}
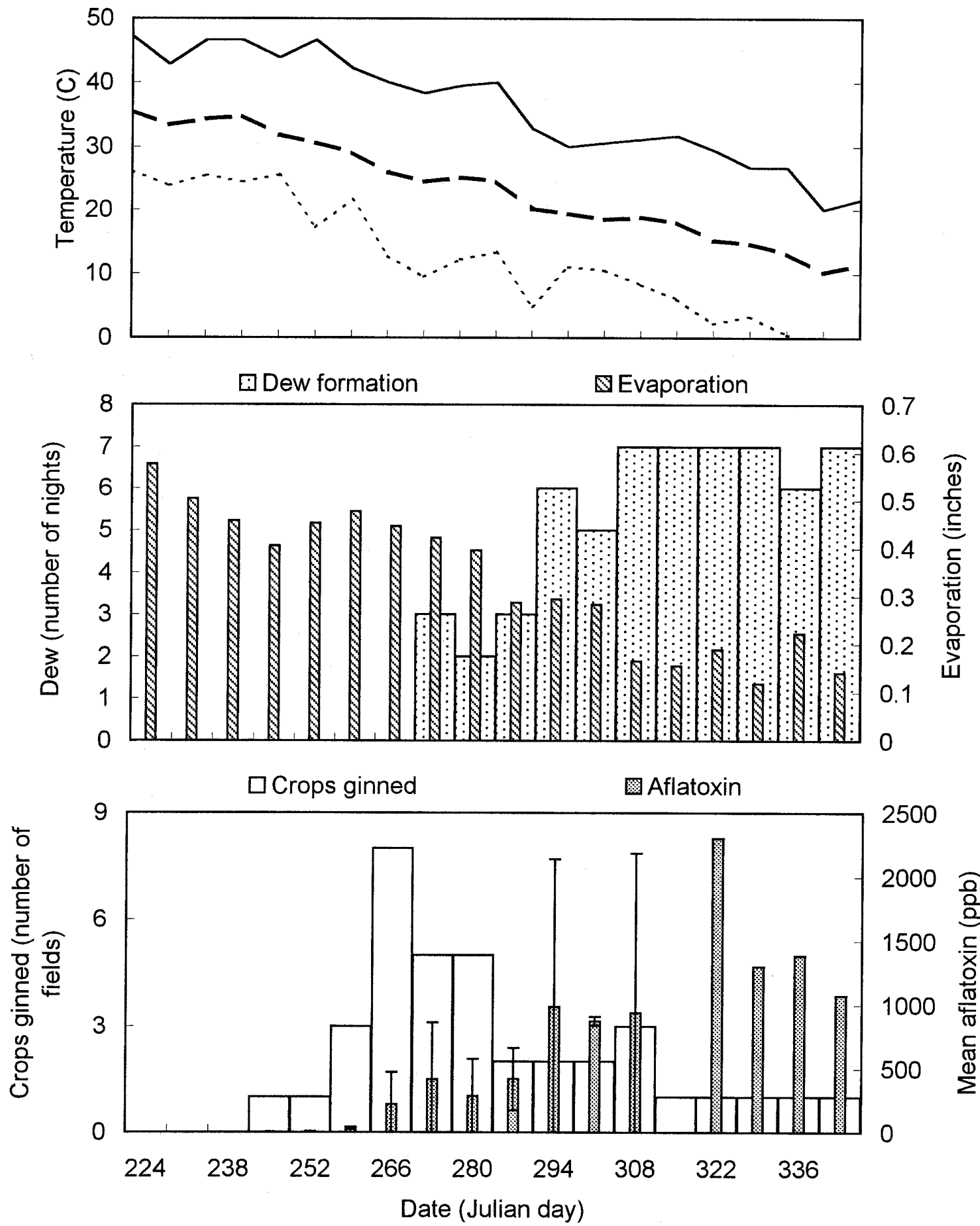

Fig. 4. Mean weekly weather data (maximum, minimum, and mean temperature, mean daily evaporation, and number of days on which dew formed) for the period August to December, 1995. Number of cottonseed lots ginned each week is shown and mean weekly aflatoxin content of seed indicated. Standard deviations are indicated for mean weekly aflatoxin only when more than two data points were used for mean estimation. 

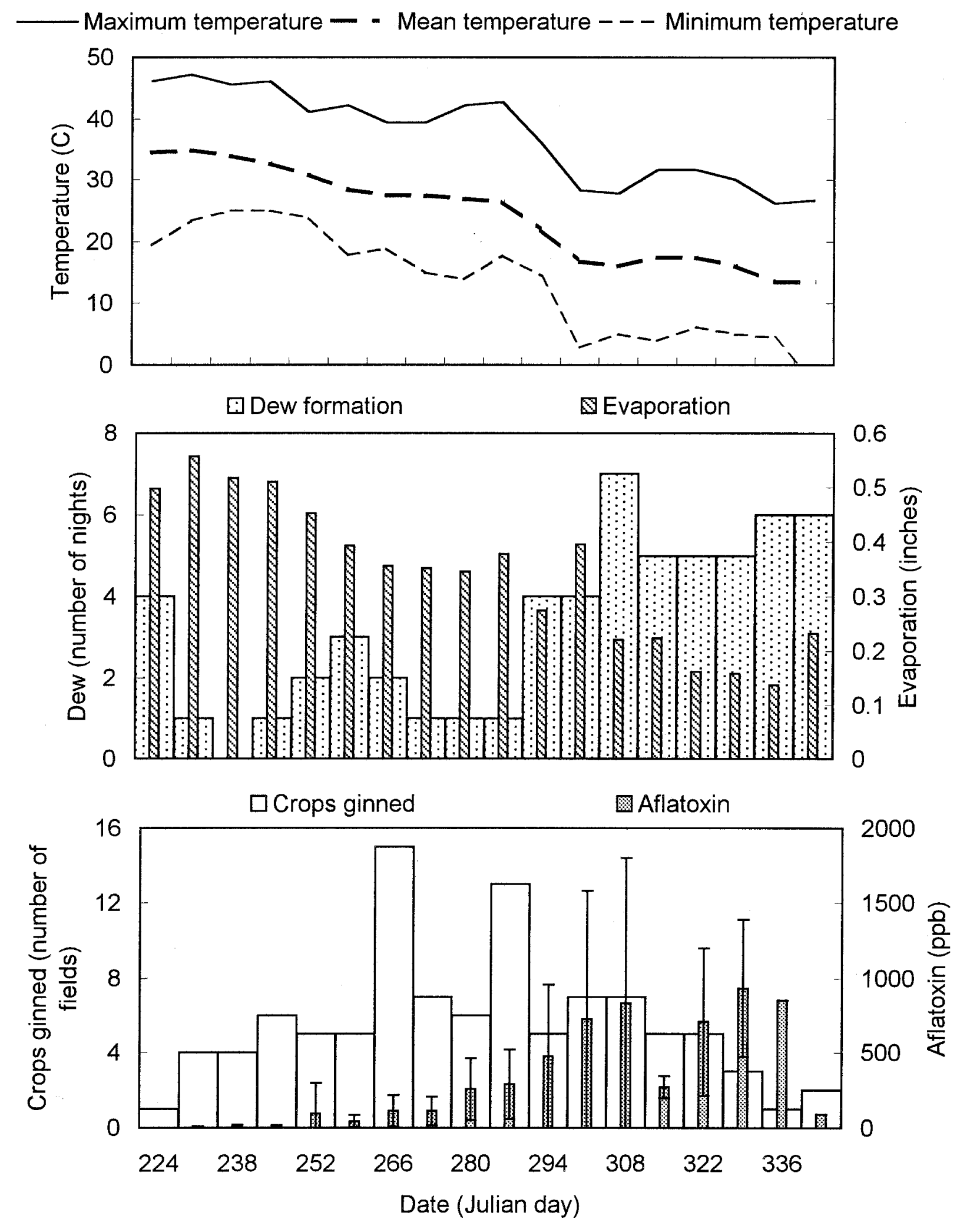

Fig. 5. Mean weekly weather data (maximum, minimum, and mean temperature, mean daily evaporation, and number of days on which dew formed) for the period August to December, 1996. Number of cottonseed lots ginned each week is shown and mean weekly aflatoxin content of seed indicated. Standard deviations are indicated for mean weekly aflatoxin only when more than two data points were used for mean estimation.

changes. The observed differences may be attributable in part to the expanded and earlier harvest period in 1996.

Early harvest will reduce the chance of later infections becoming established in both freshly split bolls and those that have been open and subject to weathering for several weeks. Once seed are colonized with a toxigenic strain of A. flavus the level of contamination will increase with time, given sufficient moisture and warmth (8). In Arizona, bolls may mature and open over several months (boll opening depends on date of anthesis, canopy position, and heat unit accumulation); therefore, both the 
Table 5. The proportion of different varieties, mean aflatoxin content and range of contamination in the Mohawk Valley, Arizona, 1996

\begin{tabular}{lcccccc}
\hline & & \multicolumn{3}{c}{ Aflatoxin (ppb) } & & \\
\cline { 3 - 5 } Cultivar & $\begin{array}{c}\text { Percent total } \\
\text { seed lots }\end{array}$ & $\begin{array}{c}\text { Mean } \\
\text { content }\end{array}$ & Predicted & Range & t test & $\begin{array}{c}\text { Harvest period } \\
\text { (Julian Day) }\end{array}$ \\
\hline Sure-Grow 125 & 32 & 212 & 142 & $0-1,334$ & NS & $225-338$ \\
Deltapine 5415 & 17 & 249 & 129 & $0-2,200$ & NS & $243-319$ \\
Sure-Grow 501 & 12 & 261 & 101 & $0-1,296$ & NS & $233-305$ \\
NuCOTN 33Bx & 8 & 413 & 667 & $92-1,000$ & NS & $221-338$ \\
Deltapine 5409 & 7 & 397 & 150 & $3-1,366$ & NS & $236-326$ \\
Stoneville-474 & 6 & 354 & 181 & $0-2,000$ & NS & $229-305$ \\
Deltapine 51 & 4 & 262 & 291 & $88-690$ & - y & $286-312$ \\
Deltapine 50 & 3 & 1,054 & 453 & $312-2,000$ & - & $300-317$ \\
Sure-Grow 404 & 2 & 288 & 60 & $76-500$ & - & $261-283$ \\
Stoneville-1001 & 1 & 975 & 1,269 & 975 & - & 326 \\
Cultivar mix ${ }^{\mathrm{z}}$ & 5 & 578 & - & $0-2,000$ & - & $221-305$ \\
Unknown & 3 & 149 & - & $109-230$ & - & $109-230$ \\
\hline
\end{tabular}

w Not significant.

x Transgenic Bt cotton.

${ }^{\mathrm{y}} t$ test not performed due to insufficient sample size.

${ }^{\mathrm{z}}$ More than one cultivar in each seed lot analyzed for aflatoxin.

Table 6. Mean aflatoxin content of transgenic $B t$ cotton and non-Bt cottons harvested in the Mohawk Valley, Arizona, in 1995 and 1996

\begin{tabular}{|c|c|c|c|c|c|c|}
\hline \multirow[b]{4}{*}{ Cultivar } & \multicolumn{6}{|c|}{ Year } \\
\hline & \multirow[b]{3}{*}{ Fields (no.) } & \multicolumn{2}{|l|}{1995} & \multicolumn{3}{|c|}{1996} \\
\hline & & \multicolumn{2}{|c|}{ Aflatoxin (ppb) } & \multirow[b]{2}{*}{ Fields $(\text { no. })^{\mathrm{x}}$} & \multicolumn{2}{|c|}{ Aflatoxin (ppb) } \\
\hline & & Mean & Range & & Mean & Range \\
\hline Bt cotton & 2 & $3,700^{y}$ & $600-7,000$ & 8 & $413(328)$ & $92-1,000$ \\
\hline Non- $B t$ cotton & 37 & $525(647)^{\mathrm{z}}$ & $2-2,375$ & 34 & $598(634)$ & $27-2,200$ \\
\hline
\end{tabular}

${ }^{x}$ The number of fields in 1996 relates to the period JD (Julian Day) 280-337 during which Bt cottons were ginned.

y In 1995, there were only two fields of $B t$ cotton, so no standard deviation is quoted for these data.

${ }^{\mathrm{z}}$ Standard deviations of the means indicated in parentheses.

first and second phases of infection may occur simultaneously on a single plant.

It was initially thought that transgenic $B t$ cottons resistant to the pink bollworm would be largely resistant to aflatoxin contamination. Early field plot studies under high pink bollworm pressure supported this $(6,11)$. However, in 1995, problems with aflatoxin contamination of $B t$ cottonseed were first observed (11). In the present study, transgenic $B t$ cottons had aflatoxin contents similar to non- $B t$ cottons. All varieties examined had seed lots exceeding $20 \mathrm{ppb}$. Resistance of $B t$ cotton to insect pests reduces the cost of delaying harvest; thus, the advent of $B t$ cotton may result in growers holding crops in the field longer (10) and, therefore, increased contamination.

In order to improve the economics of pest control and crop management, there has been a trend toward shorter season cotton (8). Early harvest date reduces the risk of aflatoxin contamination. However, growers often receive a gin average price for their seed. Thus, growers harvesting early receive the same price as those harvesting late. Greater incentive to growers to harvest early may be gained by giving a monthly or weekly average price based on harvest date. However, as the percentage of the crop harvested early increases, so will the period between harvest and ginning. If ginning is delayed, the importance of harvesting a dry crop, proper module construction, and module tarping will increase $(5,18)$. Understanding the epidemiology of aflatoxin contamination may be vital to the development of integrated programs to manage aflatoxin contamination. In combination with other methods of control, including the use of transgenic Bt cottons and biocontrol agents (9), earlier harvest dates may allow the grower an element of control over what is frequently a severe and frustrating problem.

\section{ACKNOWLEDGMENTS}

We thank Carol Morgan for initially compiling the data, and Fred Richard, Harriet Conner and the entire Growers Mohawk Gin community for the time and resources invested in this study. Bryan Vinyard kindly provided advice on the statistical analyses.

\section{LITERATURE CITED}

1. American Oil Chemists Society. 1989. Official Methods and Recommended Practices of the American Oil Chemists Society. 4th ed. Vol. 1, Sect. Aa 8-83. D. Firestone, ed. Champaign, IL.

2. Arizona Commercial Feed Law. 1981 (rev.). Title 24. Chapter 7. Article 1. Arizona Revised Statutes 24-901-24-917. Commercial Feed Regulations, Title 3-A.R.S. 24-903.B, R3-3-41-3-356.

3. Ashworth, L. J., Jr., and McMeans, J. L. 1966. Association of Aspergillus flavus and afla- toxins with a greenish yellow fluorescence of cotton seed. Phytopathology 56:1104-1105.

4. Ashworth, L. J., Jr., McMeans, J. L., and Brown, C. M. 1969. Infection of cotton by Aspergillus flavus: Time of infection and the influence of fiber moisture. Phytopathology 59:383-385.

5. Batson, W. E., Caceres, J., Cotty, P. J., and Isakeit, T. 1997. Aflatoxin levels in cottonseed at weekly intervals in Arizona, Mississippi and Texas modules. Pages 116-118 in: Proc. Beltwide Cotton Conf., Jan. 6-10 1997, New Orleans, Louisiana, Vol. 1.

6. Berberich, S. 1995. Is cotton containing the bollguard safe? Oil Mill Gaze. 101:18-19.

7. CAST. 1979. Aflatoxin and other mycotoxins: an agricultural perspective. Counc. Agric. Sci. Technol. Rep. 80

8. Cotty, P. J. 1991. Effect of harvest date on aflatoxin contamination of cottonseed. Plant Dis. 75:312-314.

9. Cotty, P. J. 1994. Influence of field application of an atoxigenic strain of Aspergillus fla$v u s$ on the populations of A. flavus infecting cotton bolls and on the aflatoxin content of cottonseed. Phytopathology 84:1270-1277.

10. Cotty, P. J. 1997. Update on methods to prevent aflatoxin formation. Oil Mill Gaze. 103: 33-38.

11. Cotty, P. J., Bock, C. H., Howell, D. R., and Tellez, A. 1997. Aflatoxin contamination of commercially grown transgenic $B t$ cottonseed. Pages 108-110 in: Proc. Beltwide Cotton Conf., Jan. 6-10 1997, New Orleans, Louisiana, Vol. 1. National Cotton Council of America, Memphis, TN.

12. Cotty, P. J., and Lee, L. S. 1989. Aflatoxin contamination of cottonseed: Comparison of pink bollworm damaged and undamaged bolls. Trop. Sci. 29:273-277.

13. Diener, U. L., Cole, R. J., Sanders, T. H., Payne, G. A., Lee, L. S., and Klich, M. A. 1987. Epidemiology of aflatoxin formation by Aspergillus flavus. Annu. Rev. Phytopathol. 25:249-270.

14. Henneberry, T. J., Bariola, L. A., and Russell, T. E. 1978. Pink bollworm: Chemical control in Arizona and relationship to infestations, seed damage, and aflatoxin in cottonseed. J. Econ. Entomol. 71:440-448.

15. Jones, R. K., Duncan, H. E., and Hamilton, P. B. 1981. Planting date, harvest date, and irrigation effects on infection and aflatoxin production by Aspergillus flavus in field corn. Phytopathology 71:810-816.

16. Lee, L. S., Lee, L. V., Jr., and Russell, T. E. 1986. Aflatoxin in Arizona cottonseed: Field inoculation of bolls by Aspergillus flavus spores in wind-driven soil. J. Am. Oil Chem. Soc. 63:530-532.

17. Park, D. L., Lee, L. S., Price, R. L., and Pohland, A. E. 1988. Review of the decontamination of aflatoxin by ammoniation: Current status and regulation. J. Assoc. Off. Anal. Chem. 71:685-703.

18. Russell, T. E. 1985. Effect of modular storage of Arizona seed cotton on levels of aflatoxin in seed. J. Am. Oil Chem. Soc. 62:515-517.

19. Russell, T. E., Watson, T. F., and Ryan, G. F. 1976. Field accumulation of aflatoxin in cottonseed as influenced by irrigation termination dates and pink bollworm infestation. Appl. Environ. Microbiol. 31:711-713.

20. Spjotvall, E., and Stoline, M. R. 1973. An extension of the t-method of multiple comparisons to include the cases with unequal sample sizes. J. Am. Stat. Assoc. 68:976978.

21. Turner, J. H., Jr., Worley, S., Jr., Ramey, H. H., Jr., Hoskinson, P. E., and Stewart, J. M. 1979. Relationship of week of flowering and parameters of boll yield in cotton. Agron. J. 71:248-251. 